\title{
Monoisotopic REE abundances in seawater and the origin of seawater tetrad effect
}

\author{
Iwao Kawabe, Takahiro ToriUmi, Atsuyuki OHTA and Noriko MiUra
}

\author{
Department of Earth and Planetary Sciences, Graduate School of Science, Nagoya University, \\ Chikusa, Nagoya 464-8602, Japan
}

(Received July 9, 1997; Accepted February 12, 1998)

\begin{abstract}
REE data for a GSJ reference carbonate sample (JDo-1) by ICP-AES, when normalized by reliable seawater REE data, exhibit fairly smooth abundance patterns except for Ce. This allows us to estimate the monoisotopic REE ( $\mathrm{Pr}, \mathrm{Tb}, \mathrm{Ho}$, and $\mathrm{Tm}$ ) concentrations compatible with the widely accepted ID-MS data for seawater REE. For the same purpose, reported seawater REE data by ICP-MS have also been used. The monoisotopic REE concentrations estimated by the two methods are in good agreement. Eventually, the seawater REE patterns normalized by chondrite or average shale show obvious concave tetrad effects of W-type. There is no room for doubt as to the seawater tetrad effect, but its origin is open to debate.

We proposed here that the tetrad effect originates from REE partitioning described by the ligandexchange reactions of $\mathrm{REE}^{3+}$ between particulate $\mathrm{REE}$ and $\operatorname{REE}\left(\mathrm{CO}_{3}\right)_{2}{ }^{-}(\mathrm{aq})$ in seawater. The particulate REE must be $\operatorname{REE}(\mathrm{OH})_{3}$-like ones rather than $\mathrm{REEO}_{1.5}$. The refined spin-pairing energy theory explains that the logarithmic equilibrium constants for the reactions exhibit a tetrad effect when Racah parameters for $4 \mathrm{f}$ electron repulsion in $\mathrm{REE}^{3+}$ ions are different between the pair of REE(III) species. We inferred that Racah parameters of $\operatorname{REE}(\mathrm{OH})_{3}$ and $\mathrm{REEO}_{1.5}$ are similar but they are commonly much smaller than those parameters of $\operatorname{REE}\left(\mathrm{CO}_{3}\right)_{2}^{-}(\mathrm{aq})$. When the reactions occur in the particulate-seawater system with high particulate concentration such as coastal seawater and estuarine water, the signature of concave tetrad effect is inevitably given to the seawater solution. Subsequent removal of excessive particulate matter from the system leaves the detectable tetrad effect in the seawater. Shale-normalized seawater REE patterns correspond roughly to the logarithmic equilibrium concentration ratios by the ligand-exchange reactions. Our proposal gives a consistent explanation for the seawater-like tetrad effects in REE patterns of marine carbonate rocks and the absence of such tetrad effects in those of deep-sea nodules. This is also related to a theoretical interpretation of the Masuda-Coryell plot in REE geochemistry.
\end{abstract}

\section{INTRODUCTION}

In recent many studies of rare earth elements (REE) in seawater (German and Elderfield, 1990; Piepgras and Jacobsen, 1992; Bertram and Elderfield, 1993; Möller et al., 1994; Zhang et al., 1994; German et al., 1995), attention has been paid mainly to vertical profiles of REE and Ce anomaly in seawater columns, correlations between REE profiles and vertical variations of hydrological parameters, and mixing processes of specific seawater-masses. Masuda and Ikeuchi (1979) and their subsequent works (Akagi et al., 1993 and references therein), however, reported that chon- drite-normalized seawater REE patterns show concave tetrad effects of W-type. This REE characteristics is not yet the focus of interest in REE geochemistry of seawater. One reason for this situation is that REE data of seawater samples analyzed by isotope dilution mass-spectrometry (ID-MS) are accepted as the most reliable ones. The four monoisotopic REE of $\mathrm{Pr}, \mathrm{Tb}, \mathrm{Ho}$, and Tm cannot be determined by ID-MS. In addition, $\mathrm{Ce}$ and Eu anomalies as well as the absence of Pm make it difficult to examine fine features of four tetrad curves (La-Nd, Pm-Gd, Gd-Ho, and Er-Lu) of seawater abundance patterns only from ID-MS data. 
Recent application of ICP mass spectrometry (ICP-MS) to REE and Y analysis of seawater samples provides more reliable data on $\mathrm{Pr}, \mathrm{Tb}$, Ho, Tm and $\mathrm{Y}$ abundances in seawater than before (Shabani et al., 1990, 1992; Zhang et al., 1994; Möller et al., 1994; Bau et al., 1995). Recently we also have improved ICP-atomic emission spectrometric (ICP-AES) analyses of REE and Y in carbonate and silicate rocks (Kawabe et al., 1994, 1995; Kawabe, 1995). Although it is difficult to apply our ICP-AES method to determinations of seawater REE, we found that our ICP-AES data for JDo-1 (a reference carbonate sample issued by Geological Survey of Japan) can be used to estimate the concentrations of $\mathrm{Pr}, \mathrm{Tb}, \mathrm{Ho}$ and $\mathrm{Tm}$ in seawater indirectly.

Our replicate ICP-AES analyses of REE in JDo-1, when normalized by reliable seawater REE data, show fairly smooth REE patterns. The simple REE relationship makes it possible to estimate Pr, $\mathrm{Tb}, \mathrm{Ho}$, and $\mathrm{Tm}$ concentrations in the seawater samples polyisotopic REE concentrations of which have been determined by ID-MS. For the same purpose, the recent ICP-MS analyses of seawater REE can also be used.

The aim of this study is to show that our REE data by ICP-AES for JDo-1 and reported seawater REE data by ICP-MS give consistent estimates of the monoisotopic REE concentrations. Eventually, the full data sets of seawater REE abundances demonstrate the lanthanide tetrad effect. In addition, we will propose an interpretation for the origin of seawater tetrad effect. We will put forward the importance of the ligand-exchange reaction of $\mathrm{REE}^{3+}$ between REE in solid particulate matter and REE(III)-carbonate complex in seawater as well as the refined spin-pairing energy theory.

\section{Replicate Analysis of REE AND Y IN JDo-1}

REE and $\mathrm{Y}$ in the carbonate reference sample of JDo-1 issued by Geological Survey of Japan have been analyzed six times by ICP-AES in the period from 1994 through 1995. The analytical method is almost the same as in Kawabe et al. (1994). In brief, aliquots of JDo-1 weighing about 5-15 $\mathrm{g}$ have been dissolved into solutions by the two methods: (i) a simple dissolution with $\mathrm{HCl}$ alone, followed by filtration to remove insoluble materials, and (ii) a total dissolution method, in which filtered insoluble materials after $\mathrm{HCl}$ dissolution are fused with $\mathrm{Na}_{2} \mathrm{CO}_{3}$ and $\mathrm{H}_{3} \mathrm{BO}_{3}$. The fusion product dissolved in $\mathrm{HCl}$ are combined with the filtrate after the $\mathrm{HCl}$ dissolution. For the sample solution by (i) or (ii), the group separation of REE and $\mathrm{Y}$ was made with coprecipitation by $\mathrm{Fe}(\mathrm{OH})_{3}$ and with cation exchange chromatography. Finally each sample solution $(0.34 \mathrm{M} \mathrm{HCl}$ solution of $20 \mathrm{ml}$ ) was measured by the SEIKO SPS-1500R ICP-AES spectrometer. A pneumatic nebulizer was used in most of measurements, but an ultrasonic nebulizer (Kawabe et al., 1995) was used partly for the determination of $\mathrm{Pr}, \mathrm{Tb}$, and $\mathrm{Tm}$ in two runs. The digestion methods of (i) and (ii) were applied to five runs and one run, respectively. No significant difference in analytical

Table 1. Replicate analyses of REE and $Y$ in GSJ reference carbonate rock of JDo-1 in this study compared with our previous results

\begin{tabular}{lcc}
\hline & $\begin{array}{c}\text { This work } \\
\left(\mathrm{ppm}, n=6^{*}\right)\end{array}$ & $\begin{array}{c}\text { Kawabe } \text { et al. }(1994) \\
\left(\mathrm{ppm}, n=6^{* *}\right)\end{array}$ \\
\hline $\mathrm{La}$ & $7.91 \pm 0.27$ & $8.28 \pm 0.63$ \\
$\mathrm{Ce}$ & $2.16 \pm 0.07$ & $2.28 \pm 0.26$ \\
$\mathrm{Pr}$ & $0.99 \pm 0.05$ & $1.10 \pm 0.06$ \\
$\mathrm{Nd}$ & $4.25 \pm 0.12$ & $4.31 \pm 0.20$ \\
$\mathrm{Sm}$ & $0.706 \pm 0.016$ & $0.772 \pm 0.069$ \\
$\mathrm{Eu}$ & $0.160 \pm 0.005$ & $0.162 \pm 0.013$ \\
$\mathrm{Gd}$ & $0.910 \pm 0.032$ & $0.955 \pm 0.090$ \\
$\mathrm{~Tb}$ & $0.128 \pm 0.009$ & $0.149 \pm 0.002$ \\
$\mathrm{Dy}$ & $0.774 \pm 0.019$ & $0.800 \pm 0.051$ \\
$\mathrm{Ho}$ & $0.176 \pm 0.005$ & $0.185 \pm 0.020$ \\
$\mathrm{Er}$ & $0.469 \pm 0.010$ & $0.487 \pm 0.037$ \\
$\mathrm{Tm}$ & $0.0562 \pm 0.0030$ & $0.0564 \pm 0.0014$ \\
$\mathrm{Yb}$ & $0.310 \pm 0.010$ & $0.323 \pm 0.016$ \\
$\mathrm{Lu}$ & $0.0435 \pm 0.0030$ & $0.0462 \pm 0.0053$ \\
$\mathrm{Y}$ & $10.2 \pm 0.3$ & $10.6 \pm 0.8$ \\
\hline
\end{tabular}

*Averages and one-sigma standard deviations for individual analyses based on the replicate analyses of $n=6$.

**The same as in the left column except for the analyses of $\mathrm{Tb}$ and $\mathrm{Tm}$. Those for $\mathrm{Tb}$ and $\mathrm{Tm}$ are calculated from three runs. 
results was found between the two methods. We calculated means and one- $\sigma$ standard deviations for REE and $Y$ contents from the results of all the runs in Table 1, along with our previous results (Kawabe et al., 1994).

\section{RESUlts AND Discussion}

Seawater-like REE characteristics of JDo-1

The chondrite-normalized REE pattern for JDo1 is shown in Fig. 1. The recent ICP-MS analyses of seawater REE (Shabani et al., 1992; Möller et al., 1994) are also shown for comparison. The two samples by Shabani et al. (1992) were collected from shallow waters in the Pacific and Japan Sea coasts. The two data sets by Möller et al. (1994) are for deep water samples $1 \mathrm{~m}$ and $10 \mathrm{~m}$ above sea-floor of the East Pacific Rise (EPR). Lu concentrations were not reported by Möller et al. (1994), because they used $\mathrm{Lu}$ as the internal standard to evaluate the recovery of REE. The bottom water samples show unusually high Eu abundances

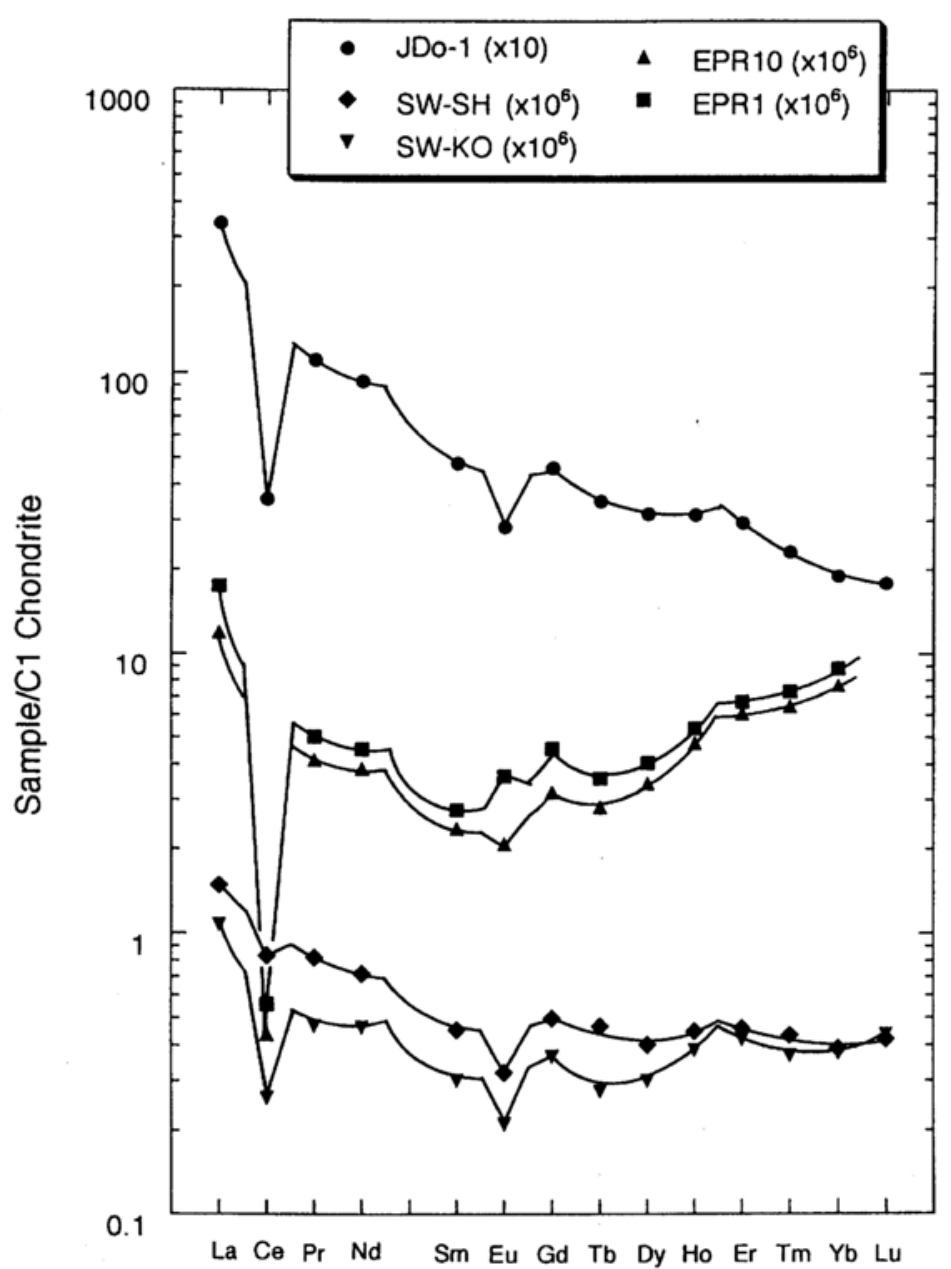

Fig. 1. The chondrite-normalized REE pattern of the GSJ reference carbonate sample (JDo-1) compared with those patterns for seawater samples by reported ICP-MS data. SW-SH: coastal seawater (depth of $1 \mathrm{~m}$ ) of Japan. Sea, Shimane, Japan (Shabani et al., 1992), SW-KO: Pacific coastal seawater at depth of $320 \mathrm{~m}$ near Kochi, Japan (Shabani et al., 1992), EPR10: filtered bottom water $10 \mathrm{~m}$ above seafloor in East Pacific Rise (Möller et al., 1994), and EPRl: filtered bottom water $1 \mathrm{~m}$ above seafloor in East Pacific Rise (Möller et al., 1994). The chondritic REE values for normalization are those for the C1 chondrite by Anders and Grevesse (1989). 
due to the influence of EPR hydrothermal fluids having large positive Eu anomalies. Except for the unusual Eu data, the two samples of EPR bottom water are similar to previous results by NAA and ID-MS for deep waters (Möller et al., 1994).

From the chondrite-normalized REE patterns in Fig. 1, it seems rather easy to say that JDo-1 and the seawater samples commonly show concave tetrad effect variations of W-type. However, we will reserve such a statement for a while. Our purpose is to estimate $\mathrm{Pr}, \mathrm{Tb}, \mathrm{Ho}$, and $\mathrm{Tm}$ concentrations compatible with the seawater REE data by ID-MS accepted widely. We will make the es- timation without a particular presumption like the tetrad effect. By the same reason, we do not adopt the mathematical method by Minami and Masuda (1997) for fitting the incomplete REE data points of the chondrite-normalized REE pattern to smooth tetrad curves. In this context, the REE patterns of JDo-1 normalized by the seawater REE analyses (Fig. 2) are more important than the results of Fig. 1. The concentration ratios for the pairs of JDo-1 and three shallow waters exhibit fairly linear variations across the REE series, although small irregularities are still recognized. The simple and smooth variations are favorable for our linear

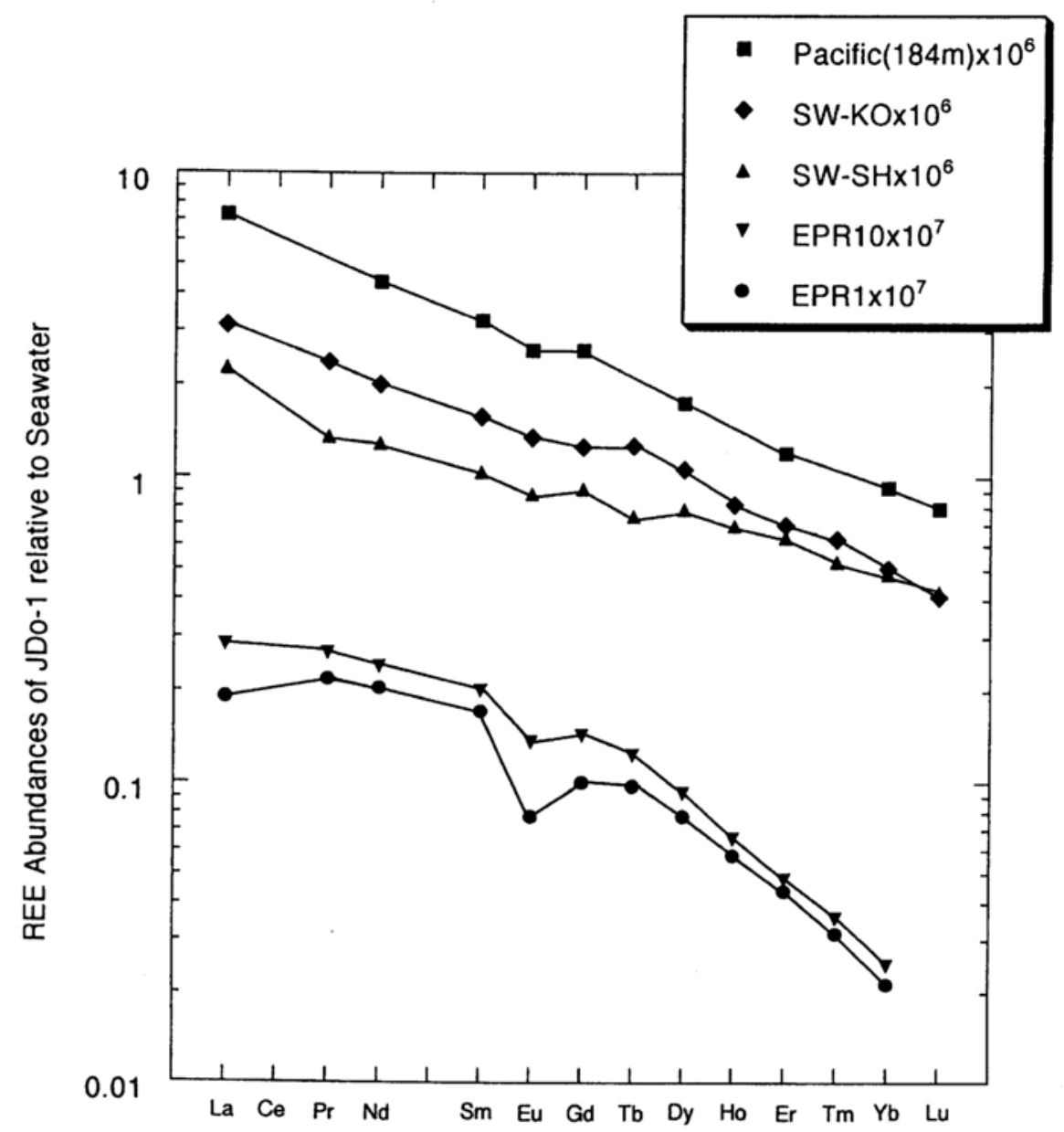

Fig. 2. REE abundances of the GSJ reference carbonate sample (JDo-1) relative to five seawater samples. The seawater sample of "Pacific (184 m)" is the shallow Pacific seawater (depth of $184 \mathrm{~m}$ ) at TPS 24 271-1 site (Piepgras and Jacobsen, 1992). The other seawater samples are the same as in Fig. 1. Because of Ce anomalies, all the data points of $\mathrm{Ce}$ are not shown. 
interpolation of the monoisotopic REE concentrations.

Estimation of monoisotopic REE abundances in seawater

In addition to our ICP-AES data for JDo-1, ICP-MS analyses of seawater samples can also be used to estimate seawater $\mathrm{Pr}, \mathrm{Tb}$, Ho and $\mathrm{Tm}$ concentrations compatible with ID-MS data. The REE pattern for one seawater sample normalized by another can exhibit a simple and monotonous variation across the series. By using our ICP-AES data for JDo-1 (Table 1) and the ICP-MS data for seawater by Shabani et al. (1992) and Möller et al. (1994) cited in Fig. 1, we have estimated the monoisotopic $\mathrm{Pr}, \mathrm{Tb}, \mathrm{Ho}$, and $\mathrm{Tm}$ concentrations compatible with the ID-MS data for Pacific waters by Piepgras and Jacobsen (1992). Each Pr concentration was estimated by linear interpolation between $\mathrm{La}$ and $\mathrm{Nd}$ data points of the REE pattern. Similarly $\mathrm{Tb}$, Ho, and $\mathrm{Tm}$ concentrations were interpolated from two neighboring data points of polyisotopic REE.

The $\mathrm{Pr}, \mathrm{Tb}, \mathrm{Ho}$, and Tm concentrations esti-

Table 2. $\mathrm{Pr}, \mathrm{Tb}, \mathrm{Ho}$, and Tm concentrations estimated for polyisotopic REE data for Pacific seawater samples (Piepgras and Jacobsen, 1992) by using our ICP-AES data for the GSJ reference carbonate rock (JDo-1) and reported ICP-MS data for four seawater samples

\begin{tabular}{|c|c|c|c|c|c|}
\hline & \multirow[t]{2}{*}{ Reference samples used* } & \multicolumn{2}{|c|}{ Average Pacific seawaters } & \multicolumn{2}{|c|}{ TPS24-271-1 } \\
\hline & & $\begin{array}{l}\text { Surface water } \\
(\mathrm{pmol} / \mathrm{kg})\end{array}$ & $\begin{array}{c}\text { Deep water } \\
(\mathrm{pmol} / \mathrm{kg})\end{array}$ & $\begin{array}{r}\text { Depth: } 0 \mathrm{~m} \\
(\mathrm{pmol} / \mathrm{kg})\end{array}$ & $\begin{array}{c}\text { Depth: } 184 \mathrm{~m} \\
(\mathrm{pmol} / \mathrm{kg})\end{array}$ \\
\hline \multirow[t]{6}{*}{$\operatorname{Pr}$} & JDo-1 & 3.67 & 7.97 & 1.06 & 1.37 \\
\hline & EPR10 & 3.50 & 7.59 & 1.02 & 1.30 \\
\hline & EPR1 & 3.35 & 7.27 & 0.973 & 1.25 \\
\hline & SW-KO & 3.60 & 7.84 & 1.05 & 1.34 \\
\hline & SW-SH & 4.01 & 8.79 & 1.17 & 1.50 \\
\hline & $($ mean $\pm s)$ & $3.62 \pm 0.25$ & $7.89 \pm 0.57$ & $1.06 \pm 0.08$ & $1.35 \pm 0.09$ \\
\hline \multirow[t]{6}{*}{$\mathrm{Tb}$} & JDo-1 & 0.749 & 1.61 & 0.295 & 0.375 \\
\hline & EPR10 & 0.697 & 1.50 & 0.274 & 0.349 \\
\hline & EPR1 & 0.676 & 1.46 & 0.267 & 0.338 \\
\hline & SW-KO & 0.681 & 1.47 & 0.267 & 0.340 \\
\hline & SW-SH & 0.813 & 1.76 & 0.320 & 0.386 \\
\hline & $($ mean $\pm s)$ & $0.724 \pm 0.057$ & $1.56 \pm 0.13$ & $0.286 \pm 0.023$ & $0.359 \pm 0.021$ \\
\hline \multirow[t]{6}{*}{ Ho } & JDo-1 & 1.49 & 3.08 & 0.563 & 0.728 \\
\hline & EPR10 & 1.52 & 3.13 & 0.573 & 0.742 \\
\hline & EPR1 & 1.50 & 3.10 & 0.566 & 0.735 \\
\hline & SW-KO & 1.57 & 3.25 & 0.597 & 0.769 \\
\hline & SW-SH & 1.55 & 3.20 & 0.583 & 0.715 \\
\hline & $($ mean $\pm s)$ & $1.53 \pm 0.03$ & $3.15 \pm 0.071$ & $0.576 \pm 0.014$ & $0.738 \pm 0.020$ \\
\hline \multirow[t]{6}{*}{$\mathrm{Tm}$} & JDo-1 & 0.718 & 1.50 & 0.229 & 0.314 \\
\hline & EPR10 & 0.693 & 1.46 & 0.222 & 0.302 \\
\hline & EPR1 & 0.698 & 1.46 & 0.223 & 0.305 \\
\hline & SW-KO & 0.669 & 1.43 & 0.218 & 0.298 \\
\hline & SW-SH & 0.764 & 1.60 & 0.244 & 0.332 \\
\hline & $($ mean $\pm s)$ & $0.708 \pm 0.036$ & $1.49 \pm 0.069$ & $0.228 \pm 0.010$ & $0.311 \pm 0.014$ \\
\hline
\end{tabular}

*Names of the seawater samples are the same as in Fig. 1. 
mated for the Pacific waters are listed in Table 2. The monoisotopic REE concentrations estimated from the carbonate rock/seawater pairs are in good agreement with those from the seawater/seawater pairs. Similarly, the monoisotopic REE concentrations for Antarctic Bottom Water (AABW) by German et al. (1995) were also estimated from the reported ID-MS data and the full REE data set for the average Pacific deep water here. Table 3 lists the seawater REE data sets supplemented by our estimation for monoisotopic REE.

Eventually, the seawater REE abundances display well-defined concave tetrad curves in their chondrite-normalized patterns (Fig. 3). The third (Gd-Ho) and fourth (Er-Lu) tetrad curves in Fig. 3 can be drawn by using the respective four data points. The first tetrad curve can also be given by the three data points of $\mathrm{La}, \mathrm{Pr}$ and $\mathrm{Nd}$ without the anomalous Ce point. It is immediately obvious that the three tetrad curves are concave. But, the data points for the second tetrad curve are only Sm and Gd because of the absence of $\mathrm{Pm}$ and $\mathrm{Eu}$ anomaly. This difficulty, however, is overcome by assuming that the first and second tetrad curves intersect at the mid point between $\mathrm{Nd}$ and $\mathrm{Pm}$ as in Kawabe (1995). This additional assumption is acceptable from the three obvious tetrad curves.

The seawater REE data by ID-MS are widely accepted, but the tetrad effects of seawater and other geochemical samples are not yet seriously considered by many geochemists (Kawabe, 1996). For example, McLennan (1994) wrote that reported tetrad effects are possibly analytical artifacts. However, the present results of Fig. 3 based on REE data by ID-MS, ICP-MS and ICP-AES offer a further line of evidence for the concave tetrad effect in the chondrite-normalized seawater REE pattern. There is no room for debate as to whether the tetrad effect of seawater is real or artifact. But there is ample room for debate over the origin of the seawater tetrad effect and its geochemical implications. We will propose an explanation for the origin of seawater tetrad effect and related geochemical observations in the following sections.

Table 3. REE abundances in Pacific waters (Piepgras and Jacobsen, 1992) and in the Antarctic bottom water (German et al., 1995) supplemented by the estimates for Pr, Tb, Ho, and Tm in this study

\begin{tabular}{|c|c|c|c|c|c|}
\hline & \multicolumn{4}{|c|}{ Pacific seawater } & \multirow{3}{*}{$\begin{array}{l}\text { Antarctic bottom water } \\
(\mathrm{pmol} / \mathrm{kg})\end{array}$} \\
\hline & \multicolumn{2}{|c|}{ Average waters } & \multicolumn{2}{|c|}{ TPS24-271-1 } & \\
\hline & $\begin{array}{l}\text { Surface water } \\
(\mathrm{pmol} / \mathrm{kg})\end{array}$ & $\begin{array}{l}\text { Deep water } \\
\text { (pmol/kg) }\end{array}$ & $\begin{array}{l}\text { Depth: } 0 \mathrm{~m} \\
(\mathrm{pmol} / \mathrm{kg})\end{array}$ & $\begin{array}{l}\text { Depth: } 184 \mathrm{~m} \\
\quad(\mathrm{pmol} / \mathrm{kg})\end{array}$ & \\
\hline $\mathrm{La}$ & 25.7 & 53.8 & 5.82 & 7.83 & 54 \\
\hline $\mathrm{Ce}$ & 5.66 & 5.89 & 4.98 & 4.88 & 12 \\
\hline $\operatorname{Pr}^{*}$ & 3.62 & 7.89 & 1.06 & 1.35 & 8.16 \\
\hline $\mathrm{Nd}$ & 16.2 & 36.2 & 5.41 & 6.75 & 38 \\
\hline $\mathrm{Sm}$ & 3.04 & 6.84 & 1.14 & 1.43 & 7.1 \\
\hline $\mathrm{Eu}$ & 0.811 & 1.79 & 0.320 & 0.403 & 1.8 \\
\hline Gd & 4.49 & 9.69 & 1.75 & 2.21 & 8.8 \\
\hline $\mathrm{Tb}^{*}$ & 0.724 & 1.56 & 0.286 & 0.359 & 1.37 \\
\hline Dy & 5.29 & 11.4 & 2.10 & 2.70 & 9.7 \\
\hline Ho* & 1.53 & 3.15 & 0.576 & 0.738 & 2.69 \\
\hline Er & 4.95 & 9.82 & 1.78 & 2.32 & 8.4 \\
\hline Tm* & 0.708 & 1.49 & 0.228 & 0.311 & 1.24 \\
\hline $\mathrm{Yb}$ & 4.73 & 10.5 & 1.34 & 1.92 & 8.5 \\
\hline $\mathrm{Lu}$ & 0.897 & 1.93 & 0.213 & 0.312 & 1.4 \\
\hline
\end{tabular}

*The Pr, Tb, Ho, and Tm concentrations in the four Pacific waters are estimated as in Table 2. The monoisotopic REE concentrations in $A A B W$ are estimated from its original ID-MS data set normalized by the full REE data set for the average Pacific deep water in this table. 


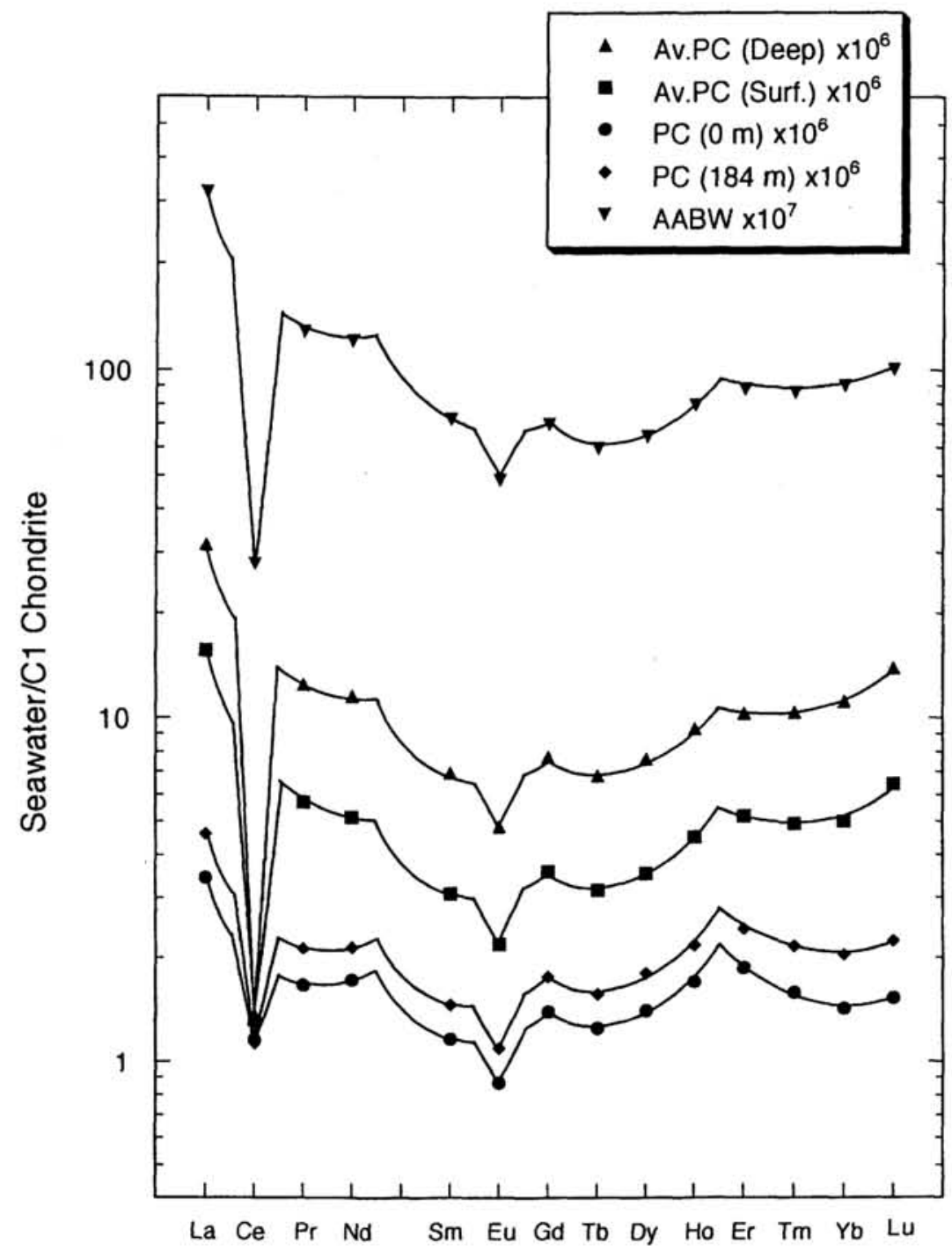

Fig. 3. Chondrite-normalized REE patterns of Pacific seawater samples (Piepgras and Jacobsen, 1992) and the Antarctic bottom water (German et al., 1995). The reported ID-MS data are supplemented by our estimates for $\mathrm{Pr}, \mathrm{Tb}, \mathrm{Ho}$, and $\mathrm{Tm}$ in this study (see Table 3). The chondritic REE values for normalization are those for the C1 chondrite by Anders and Grevesse (1989).

Why are the seawater-normalized REE patterns of JDo-1 so smooth?

The concave tetrad effects in the chondritenormalized REE patterns for seawater and the carbonate reference rock (Figs. 1 and 3) are so conspicuous in contrast to the smooth and fairly monotonous variations of the logarithmic concentration ratios between the carbonate rock and seawater samples (Fig. 2). This is a key to under- standing the origin of tetrad effects of seawater and the carbonate rock.

Another key is the refined spin-pairing energy theory (Jørgensen, 1979; Reisfeld and Jørgensen, 1977; Kawabe, 1992, 1995). According to the theory, Racah $\left(E^{1}\right.$ and $E^{3}$ ) parameters for $4 f$ electron repulsion in $\mathrm{REE}^{3+}$ decrease with increasing covalency of bondings of $\mathrm{REE}^{3+}$ with ligands in various REE(III) complexes. Racah parameters can 
be determined from $4 \mathrm{f}$ electronic spectra of individual REE(III) complexes, but the REE(III) complexes Racah parameters of which are precisely known are still limited. The spectroscopic parameters are also related to thermodynamic ones. When the Racah parameters are different between a coexisting pair of REE(III) complex series, the differences appear as the tetrad effect in the logarithmic partition coefficients of REE between the pair. The polarity of tetrad effect with concavity or convexity designates which REE(III) complex series has greater Racah parameters than the other. When the Racah parameters are exactly the same between them, no tetrad effect is expected in the logarithmic partition coefficients.

The $\mathrm{REE}^{3+}$ ions are present in seawater solution as REE(III)-carbonate complexes of $\mathrm{REECO}_{3}{ }^{+}(\mathrm{aq})$ and $\operatorname{REE}\left(\mathrm{CO}_{3}\right)_{2}{ }^{-}(\mathrm{aq})$. The most dominant REE species is $\operatorname{REE}\left(\mathrm{CO}_{3}\right)_{2}{ }^{-}(\mathrm{aq})$, the next is $\mathrm{REECO}_{3}{ }^{+}(\mathrm{aq})$, and the other species including $\mathrm{REE}^{3+}(\mathrm{aq})$ are less important (Millero, 1992; Lee and Byrne, 1993). The $\mathrm{REE}^{3+}$ ions of $\operatorname{REE}\left(\mathrm{CO}_{3}\right)_{2}{ }^{-}$ (aq) are coordinated by $\mathrm{CO}_{3}{ }^{2-}$ ions and water molecules in their first coordination spheres. The $\mathrm{REE}^{3+}$ ions incorporated in carbonate minerals are presumably ligated by $\mathrm{CO}_{3}{ }^{2-}$ ions. Thus $\mathrm{REE}^{3+}$ ions in seawater and carbonate rocks are coordinated commonly by $\mathrm{CO}_{3}{ }^{2-}$ ions. The coordination states of $\mathrm{REE}^{3+}$ ions in carbonate rocks are not well understood. However, in the laboratory experiments of REE partitioning between calcite and seawater solution (Zhong and Mucci, 1995), the charge-balanced substitution of $\mathrm{REE}^{3+}$ with $\mathrm{Na}^{+}$ for $\mathrm{Ca}^{2+}$ sites of calcite is suggested. Water molecules are also present in the first coordination spheres of the aqueous REE(III) carbonate complexes, but it may be unlikely that water molecules are involved in the first coordination spheres of $\mathrm{REE}^{3+}$ ions occupying Ca-sites of carbonate minerals. In this respect, the bondings and coordination states of $\mathrm{REE}^{3+}$ ions in carbonate rocks and aqueous REE(III) carbonate complexes are not exactly the same, but quite similar. Hence, the Racah parameters for $\mathrm{REE}^{3+}$ ions may not be so different between the two species. This may be the reason why REE concentrations of the car- bonate rock relative to seawater (Fig. 2) exhibit fairly smooth variations. Analytical results of REE similar to JDo-1 here are frequently seen in Japanese Permian carbonate rocks from different locations (Kawabe et al., 1991, 1992). More detailed discussion will be reported elsewhere.

Chondrite or "average crustal rock": Which is better to normalize seawater REE?

In order to understand the tetrad effects in chondrite-normalized REE patterns of Fig. 1, we must take it into consideration that the chondritic material is not in a direct reaction relation with seawater or marine carbonate rocks. Therefore we suppose the following successive chains of REE partitioning reactions between, at least, the three geochemical materials;

$$
\begin{aligned}
& \text { Chondritic material } \Leftrightarrow \text { Crustal rocks, } \\
& \text { Crustal rocks } \Leftrightarrow \text { Seawater, }
\end{aligned}
$$

Seawater $\Leftrightarrow$ Carbonate rocks.

The reaction chains, though they are conceptual, link the chondritic REE abundances with the REE concentrations in seawater and marine carbonate rocks. We have already suggested the reason why the reaction step (3) does not produce marked tetrad effects in relation to the results of Fig. 2. We focus our attention on the reaction steps of (1) and (2). The reaction chains involving "crustal rocks" are necessary to connect the chondritic REE with the seawater REE. Additional reaction steps can be placed between (1) and (3) for more realistic modeling, but we put only one reaction step of (2) for simplification.

The conceptual model of reaction chains makes it clear that the chondrite-normalized REE pattern of each seawater sample (Figs. 1 and 3) expresses the total REE fractionation in the two reaction steps of (1) and (2). The REE fractionation in the step (1) occurs in the magmatic condition, and corresonds to the chondrite-normalized REE patterns for crustal rocks, as exemplified by those patterns for average shales like NASC and PAAS 
by Gromet et al. (1984) and Taylor and McLennan (1988), respectively. Tetrad effect variations are little conspicuous in the chondrite-normalized REE patterns of the average shales, although they indeed involve small tetrad effect variations (Kawabe, 1996). Hence, the REE fractionation in the reaction step (2) under the earth's surface condition is responsible for chondrite-normalized seawater REE abundances characterized by concave tetrad effects. In order to consider the reaction to produce the tetrad effect, the seawater REE pattern normalized by "average crustal rock" is more important than its chondrite-normalized
one.We showed the REE patterns for three seawater samples normalized by the average shale of NASC in Fig. 4, where the average Pacific deep water is also normalized by the average Pacific deep-sea nodule for comparison. The REE data for NASC and the average Pacific deep-sea nodule adopted in this study are listed in Table 4 . Here we use the REE data of NASC as those for an average crustal rock. The seawater REE patterns, even when normalized by NASC, commonly exhibit concave tetrad effect variations, at least, in the first, second, and third tetrad curves (Fig. 4). The slightly irregular variations of the fourth tet-

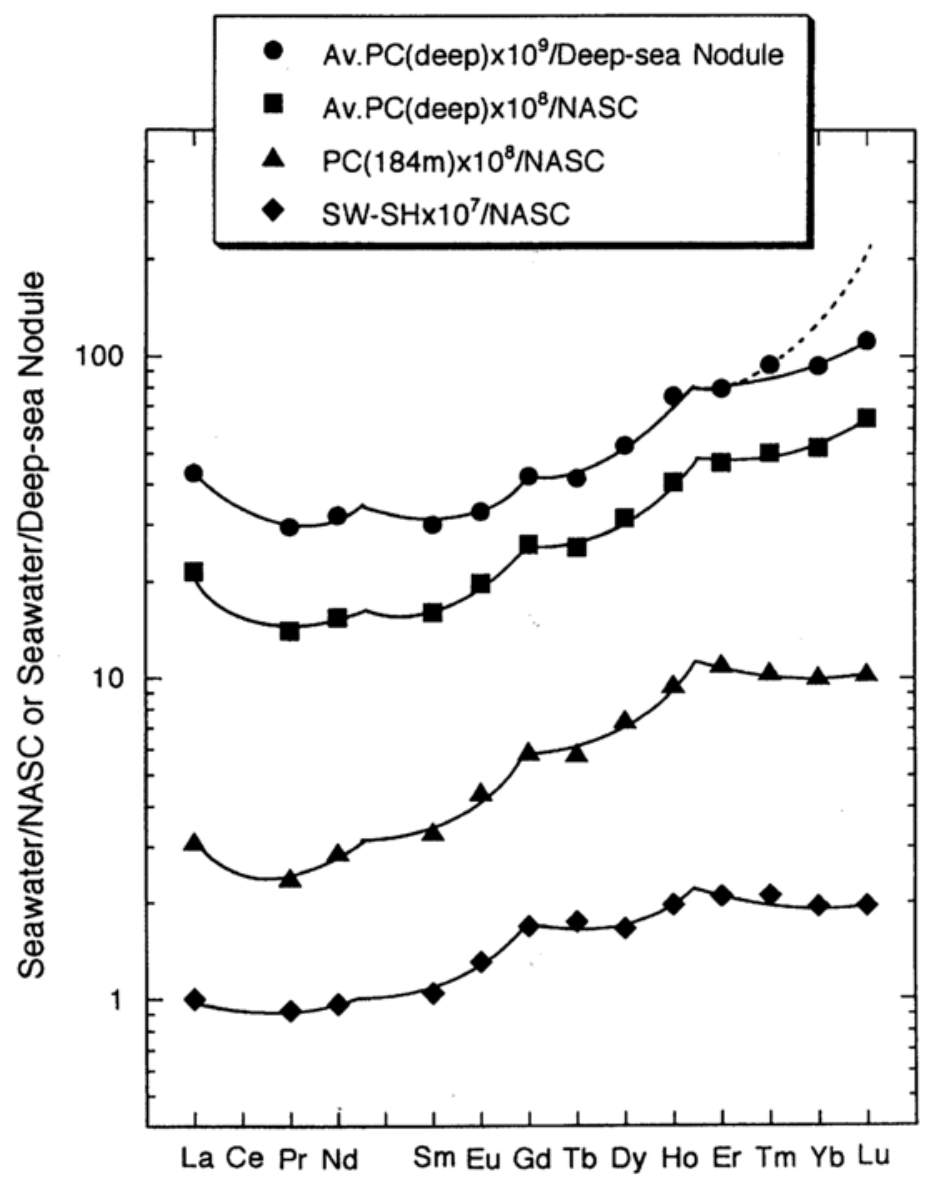

Fig. 4. REE patterns for Pacific waters normalized by the average shale of NASC. The average Pacific deep water is normalized also by the average Pacific deep-sea nodule. The REE data of NASC and the average Pacific deep-sea nodule for normalization are listed in Table 4. The dotted curve indicates the possible fourth tetrad curve when corrected for slightly distinct coordination states of $\mathrm{Tm}^{3+}, \mathrm{Yb}^{3+}$, and $\mathrm{Lu}^{3+}$ ions in hydroxide-like REE series (see text). All the data points for Ce are not shown. 
Table 4. REE data for the North American shale composite (NASC) and the average Pacific deepsea nodule used in this study

\begin{tabular}{lcc}
\hline & $\begin{array}{c}\text { NASC* } \\
(\mathrm{ppm})\end{array}$ & $\begin{array}{c}\text { Average Pacific deep-sea nodule** } \\
(\mathrm{ppm})\end{array}$ \\
\hline $\mathrm{La}$ & 34.7 & 172 \\
$\mathrm{Ce}$ & 71.3 & 1210 \\
$\mathrm{Pr}$ & 7.9 & 38.6 \\
$\mathrm{Nd}$ & 33.6 & 164 \\
$\mathrm{Sm}$ & 6.38 & 34.6 \\
$\mathrm{Eu}$ & 1.37 & 8.32 \\
$\mathrm{Gd}$ & 5.83 & 35.9 \\
$\mathrm{~Tb}$ & 0.97 & 6.10 \\
$\mathrm{Dy}$ & 5.88 & 35.0 \\
$\mathrm{Ho}$ & 1.27 & 6.98 \\
$\mathrm{Er}$ & 3.49 & 20.7 \\
$\mathrm{Tm}$ & 0.50 & 2.69 \\
$\mathrm{Yb}$ & 3.26 & 19.5 \\
$\mathrm{Lu}$ & 0.523 & 3.03 \\
\hline
\end{tabular}

*All the values except Pr and Tm ones are averages for analytical results of NASC summarized in Gromet et al. (1984). The reason to adopt the $\mathrm{Pr}$ and Tm analyses here is given in Kawabe (1996).

**REE analyses for four deep-sea nodules from northwestern Pacific in this laboratory have been averaged. The individual data will be published elsewhere (Ohta et al., in preparation). The term "average" is conventional, and does not mean that this data set is recommended for Pacific deepsea nodules.

rad in Fig. 4 will be discussed in the later section. The REE fractionations given by the logarithmic REE concentration ratios in Fig. 4 are to be explained by the reaction step (2).

\section{REE partitioning reaction between "average} crustal rock" and seawater solution

$\mathrm{REE}^{3+}$ ions in seawater are present as their carbonate complexes. The most dominant species is $\operatorname{REE}\left(\mathrm{CO}_{3}\right)_{2}{ }^{-}(\mathrm{aq})$ as noted above. On the other hand, it is difficult to specify the coordination state of $\mathrm{REE}^{3+}$ in crustal rocks in reaction with seawater. We tentatively assume that $\mathrm{REE}^{3+}$ ions in crustal rocks are coordinated by $\mathrm{O}^{2-}$ ions probably as in their sesquioxides of REEO $_{1.5}$. Then the reaction step (2) can be written by using the reaction for REE partitioning between them;

$$
\begin{aligned}
\mathrm{MO}_{1.5}(\mathrm{ss}) & +2 \mathrm{CO}_{3}{ }^{2-}(\mathrm{aq})+3 \mathrm{H}^{+}(\mathrm{aq})^{\prime} \\
& =\mathrm{M}\left(\mathrm{CO}_{3}\right)_{2}{ }^{-}(\mathrm{aq})+(3 / 2) \mathrm{H}_{2} \mathrm{O}(\mathrm{l}),
\end{aligned}
$$

where $\mathrm{MO}_{1.5}(\mathrm{ss})$ stands for $\mathrm{REE}^{3+}$ ions incorporated in an average crustal rock material. We assume further that $\mathrm{MO}_{1.5}(\mathrm{ss})$ can be treated as a trace component in the solid solution of an average crustal rock material. The standard state chemical potential for the REE component is given by pure sesquioxide of $\operatorname{REEO}_{1.5}$. The reaction (4) designates the changes in bonding and coordination state of each $\mathrm{REE}^{3+}$ ion. This is a ligand-exchange reaction of $\mathrm{REE}^{3+}$ ion between the pair of REE(III) complex series (Kawabe, 1992, 1995). From the equilibrium constant for (4), RTInK $=-\Delta G^{\circ}$, we obtain the following expression;

$$
\begin{aligned}
& 2.303 \mathrm{RT} \log \left\{\mathrm{a}\left(\mathrm{M}\left(\mathrm{CO}_{3}\right)_{2}{ }^{-}, \mathrm{aq}\right) / \mathrm{a}\left(\mathrm{MO}_{1.5}\right)\right\} \\
&=\left\{\Delta \mathrm{G}_{\mathrm{f}}^{\circ}\left(\mathrm{MO}_{1.5}\right)-\Delta \mathrm{G}_{\mathrm{f}}^{\circ}\left(\mathrm{M}\left(\mathrm{CO}_{3}\right)_{2}{ }^{-}, \mathrm{aq}\right)\right\} \\
&+ \text { constant }
\end{aligned}
$$

where each $\Delta \mathrm{G}_{\mathrm{f}}^{\circ}$ stands for the standard Gibbs free energy of formation for the component. The thermodynamic quantities for $\mathrm{CO}_{3}{ }^{2-}(\mathrm{aq}), \mathrm{H}^{+}(\mathrm{aq})$, and $\mathrm{H}_{2} \mathrm{O}(\mathrm{l})$ are collectively expressed in the constant term, since they do not change even when $\mathrm{M}$ of one REE is replaced by another.

The activity ratio on the left hand side of Eq. (5) is written by the ratio of the practical concentrations:

$$
\begin{aligned}
& \log \left\{\mathrm{m}\left(\mathrm{M}\left(\mathrm{CO}_{3}\right)_{2}{ }^{-}, \mathrm{aq}\right) / \mathrm{m}\left(\mathrm{MO}_{1.5}\right)\right\} \\
& =\left\{\Delta \mathrm{G}_{\mathrm{f}}^{\circ}\left(\mathrm{MO}_{1.5}\right)-\Delta \mathrm{G}_{\mathrm{f}}^{\circ}\left(\mathrm{M}\left(\mathrm{CO}_{3}\right)_{2}{ }^{-}, \mathrm{aq}\right)\right\} / 2.303 \mathrm{RT} \\
& +\log \left\{\lambda\left(\mathrm{MO}_{1.5}\right) / \chi\left(\mathrm{M}\left(\mathrm{CO}_{3}\right)_{2}{ }^{-}, \mathrm{aq}\right)\right\} \\
& +\log \left\{\mathrm{f}\left(\mathrm{MO}_{1.5}\right)\right\}+\text { constant, }
\end{aligned}
$$

where $\mathrm{m}\left(\mathrm{M}\left(\mathrm{CO}_{3}\right)_{2}^{-}\right.$, aq) and $\mathrm{m}\left(\mathrm{MO}_{1.5}\right)$ denote, respectively, the concentration of $\operatorname{REE}\left(\mathrm{CO}_{3}\right)_{2}{ }^{-}(\mathrm{aq})$ in seawater and the REE concentration in the average crustal rock material expressed in mole $/ \mathrm{kg}$. $\lambda\left(\mathrm{MO}_{1.5}\right)$ and $\chi\left(\mathrm{M}\left(\mathrm{CO}_{3}\right)_{2}{ }^{-}\right.$, aq $)$are activity coefficients. $\mathrm{f}\left(\mathrm{MO}_{1.5}\right)$ is the factor for converting the concentration value of $\mathrm{m}\left(\mathrm{MO}_{1.5}\right)$ in mole $/ \mathrm{kg}$ unit to the mole fraction of $\mathrm{X}\left(\mathrm{MO}_{1.5}\right)$ :

$$
\begin{aligned}
& \mathrm{a}\left(\mathrm{MO}_{1.5}\right)=\lambda\left(\mathrm{MO}_{1.5}\right) \cdot \mathrm{X}\left(\mathrm{MO}_{1.5}\right) \\
& \quad=\lambda\left(\mathrm{MO}_{1.5}\right) \cdot \mathrm{f}\left(\mathrm{MO}_{1.5}\right) \cdot \mathrm{m}\left(\mathrm{MO}_{1.5}\right) .
\end{aligned}
$$

The total REE in seawater is approximately 
the sum of the two carbonate complexes as noted above:

$$
\begin{aligned}
& \mathrm{m}(\mathrm{M}, \text { tot. }) \\
& \quad=\mathrm{m}\left(\mathrm{MCO}_{3}{ }^{+}, \mathrm{aq}\right)+\mathrm{m}\left(\mathrm{M}\left(\mathrm{CO}_{3}\right)_{2}{ }^{-}, \mathrm{aq}\right) .
\end{aligned}
$$

The complex formation constants $\left(\mathrm{K}_{1}\right.$ and $\left.\mathrm{K}_{2}\right)$ for $\mathrm{MCO}_{3}{ }^{+}(\mathrm{aq})$ and $\mathrm{M}\left(\mathrm{CO}_{3}\right)_{2}{ }^{-}(\mathrm{aq})$ are defined by the equilibrium constants for the following reactions, respectively;

$$
\begin{aligned}
& \mathrm{M}^{3+}(\mathrm{aq})+\mathrm{CO}_{3}{ }^{2-}(\mathrm{aq})=\mathrm{MCO}_{3}{ }^{+}(\mathrm{aq}), \\
& \mathrm{M}^{3+}(\mathrm{aq})+2 \mathrm{CO}_{3}{ }^{2-}(\mathrm{aq})=\mathrm{M}\left(\mathrm{CO}_{3}\right)_{2}{ }^{-}(\mathrm{aq}) .
\end{aligned}
$$

By using $\mathrm{K}_{1}, \mathrm{~K}_{2}$, and the other thermodynamic parameters for (8) and (9), $\mathrm{m}\left(\mathrm{MCO}_{3}{ }^{+}, \mathrm{aq}\right)$ in Eq. (7) is eliminated:

$$
\mathrm{m}(\mathrm{M}, \text { tot. })=(\phi+1) \cdot \mathrm{m}\left(\mathrm{M}\left(\mathrm{CO}_{3}\right)_{2}^{-}, \mathrm{aq}\right),
$$

where

$$
\begin{aligned}
& \phi=\left(\mathrm{K}_{1} / \mathrm{K}_{2}\right)\left[1 / \mathrm{a}\left(\mathrm{CO}_{3}{ }^{2-}, \mathrm{aq}\right)\right] \\
& \cdot\left[\gamma\left(\mathrm{M}\left(\mathrm{CO}_{3}\right)_{2}{ }^{-}, \mathrm{aq}\right) / \gamma\left(\mathrm{MCO}_{3}{ }^{+}, \mathrm{aq}\right)\right] \text {. }
\end{aligned}
$$

Hence, $\log \left\{\mathrm{m}\left(\mathrm{M}\left(\mathrm{CO}_{3}\right)_{2}{ }^{-}, \mathrm{aq}\right) / \mathrm{m}\left(\mathrm{MO}_{1.5}\right)\right\}$ in Eq. (6) can be written by using the total REE concentration in seawater of $\mathrm{m}(\mathrm{M}$, tot.) as follows:

$$
\begin{aligned}
& \log \left\{\mathrm{m}(\mathrm{M}, \text { tot. }) / \mathrm{m}\left(\mathrm{MO}_{1.5}\right)\right\} \\
& \left.=\left\{\Delta \mathrm{G}_{\mathrm{f}}^{\circ}\left(\mathrm{MO}_{1.5}\right)-\Delta \mathrm{G}_{\mathrm{f}}^{\circ} \mathrm{f}\left(\mathrm{CO}_{3}\right)_{2}{ }^{-}, \mathrm{aq}\right)\right\} / 2.303 \mathrm{RT} \\
& +\log (\phi+1)+\log \left\{\lambda\left(\mathrm{MO}_{1.5}\right) / \gamma\left(\mathrm{M}\left(\mathrm{CO}_{3}\right)_{2}{ }^{-}, \mathrm{aq}\right)\right\} \\
& +\log \left\{\mathrm{f}\left(\mathrm{MO}_{1.5}\right)\right\}+\text { constant. }
\end{aligned}
$$

The left hand side of Eq. (12), $\log \{\mathrm{m}(\mathrm{M}$, tot.) $)$ $\left.\mathrm{m}\left(\mathrm{MO}_{1.5}\right)\right\}$, is analogous to the seawater REE pattern normalized by NASC in Fig. 4. The concave tetrad effects in Fig. 4 could be explained by referring to Eq. (12) as below.

Origin of seawater tetrad effect: A simple interpretation

According to the refined spin-pairing energy theory outlined before, the variation of

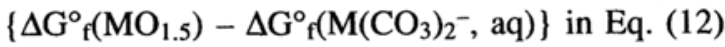

across the lanthanide series shows a concave tetrad effect, when Racah $E^{1}$ and $E^{3}$ parameters for $\mathrm{REEO}_{1.5}$ in the average crustal rock material are significantly smaller than those for $\operatorname{REE}\left(\mathrm{CO}_{3}\right)_{2}{ }^{-}$ (aq). Indeed, it is well-known that the sequioxide series of REEO $_{1.5}$ have fairly smaller Racah parameters than the other REE(III) complex series (Jørgensen, 1971; Kawabe, 1992). Hence the observed concave tetrad effect variations in Fig. 4 are attributed directly to the significantly smaller Racah parameters in $\mathrm{REEO}_{1.5}$ relative to $\operatorname{REE}\left(\mathrm{CO}_{3}\right)_{2}{ }^{-}$(aq).

The remaining terms in Eq. (12) are not strictly constant across the series, but they conceivably cannot contribute greatly to the observed tetrad effects. The variation of $\log (\phi+1)$ in Eq. (12) across the series can be evaluated from $\mathrm{K}_{1}$ and $\mathrm{K}_{2}$ for REE(III)-carbonate complexation (Millero, 1992) and $\mathrm{a}\left(\mathrm{CO}_{3}{ }^{2-}, \mathrm{aq}\right)$ in seawater (Millero, 1979). We can assume that $\gamma\left(\mathrm{M}_{\left.\left(\mathrm{CO}_{3}\right)_{2}{ }^{-}, \mathrm{aq}\right) \approx} \approx\right.$ $\chi\left(\mathrm{MCO}_{3}{ }^{+}\right.$, aq) (Cantrell and Byrne, 1987), and then we input $\mathrm{a}\left(\mathrm{CO}_{3}{ }^{2-}, \mathrm{aq}\right)=\chi\left(\mathrm{CO}_{3}{ }^{2-}, \mathrm{aq}\right) \cdot \mathrm{m}\left(\mathrm{CO}_{3}{ }^{2-}, \mathrm{aq}\right)$ $\approx 0.2 \times 2.2 \times 10^{-4}$ for seawater into Eq. (11). As a result, the estimated value of $\log (\phi+1)$ decreases fairly monotonously from 0.24 to 0.03 with going from $\mathrm{La}$ to $\mathrm{Lu}$. The term $\log (\phi+1)$ cannot explain the conspicuous tetrad effects in Fig. 4 at all.

Thus the reaction (4) can explain the origin of tetrad effect of seawater. In a strict sense, however, we must place an additional condition concerning the REE mass balance in the reaction system: the total particulate REE $\left(=\mathrm{C}_{\mathrm{p}} \cdot \mathrm{m}\left(\mathrm{MO}_{1.5}\right)\right.$, where $\mathrm{C}_{\mathrm{p}}$ denotes the mass fraction of particulate matter in seawater) is far greater than that of total REE in seawater solution $\left(=\mathrm{m}\left(\mathrm{MCO}_{3}{ }^{+}, \mathrm{aq}\right)+\mathrm{m}\left(\mathrm{M}\left(\mathrm{CO}_{3}\right)_{2}{ }^{-}\right.\right.$ , aq)),

$$
\begin{aligned}
& \mathrm{C}_{\mathrm{p}} \cdot \mathrm{m}\left(\mathrm{MO}_{1.5}\right) \\
& \gg \mathrm{m}\left(\mathrm{MCO}_{3}{ }^{+}, \mathrm{aq}\right)+\mathrm{m}\left(\mathrm{M}\left(\mathrm{CO}_{3}\right)_{2}^{-}, \mathrm{aq}\right) \text {. }
\end{aligned}
$$

This is necessary to reproduce similar seawater tetrad effects without changing the particulate REE concentrations virtually. A specific geochemical situation for the constraint of (13) must be the seawater with high concentration of detritus par- 
ticulate matter such as shallow coastal seawater including estuarine water. REE concentrations in particulate matter may be $10^{6}-10^{7}$ times greater than that those in seawater solution (see Fig. 4). Hence the seawater with $C_{p} \gg 0.1 \sim 0.01 \%$ is favored. The process to separate excessive detritus particulate matter from the system is also important. This is realized by sedimentation of particulate matter as it is conveyed in water circulation. The more effective separation of particulate matter can produce the more marked tetrad effect signature in seawater.

The origin of observed seawater tetrad effects could be understood by assuming that sesquioxidelike REE of detritus particulate are reacting with REE-carbonate complexes in seawater. However, the particulate REE more reactive with seawater REE may be hydroxide-like REE rather than sesquioxide-like ones. We will consider this point in the next.

\section{Origin of seawater tetrad effect: Particulate REE of $\mathrm{REE}(\mathrm{OH})_{3}(\mathrm{ss})$}

When the physical separation of detritus particulate accompanies removal of significant amounts of authigenic phases enriched in REE like Fe-Mn oxyhydroxides, the following reaction must be considered,

$$
\begin{aligned}
\mathrm{M}(\mathrm{OH})_{3}(\mathrm{ss})+ & 2 \mathrm{CO}_{3}{ }^{2-}(\mathrm{aq})+3 \mathrm{H}^{+}(\mathrm{aq}) \\
& =\mathrm{M}\left(\mathrm{CO}_{3}\right)_{2}{ }^{-}(\mathrm{aq})+3 \mathrm{H}_{2} \mathrm{O}(\mathrm{l}),
\end{aligned}
$$

where $\mathrm{M}(\mathrm{OH})_{3}(\mathrm{ss})$ stands for each $\mathrm{REE}^{3+}$ incorporated into the $\mathrm{Fe}-\mathrm{Mn}$ oxyhydroxides. Marine authigenic Fe-Mn oxyhydroxides such as deep-sea ferromanganese nodules show shale-like REE patterns except for nomalous Ce. In Fig. 4, we show the REE pattern of average Pacific deep water normalized by Pacific deep-sea nodule. The concave tetrad effect variation is obvious in the REE pattern of deep water normalized by either NASC or the deep-sea nodule. Hence, the ligandexchange reaction of (14) can also produce the tetrad effect very similar to that by the reaction (4). More detailed discussion of this point has been made elsewhere (Kawabe and Ohta, 1996). It is essential that the Racah parameters for $\mathrm{REE}^{3+}$ ions in $\mathrm{REE}(\mathrm{OH})_{3}$ series are close to those parameters in $\mathrm{REEO}_{1.5}$ series but much smaller than those in $\operatorname{REE}\left(\mathrm{CO}_{3}\right)_{2}{ }^{-}(\mathrm{aq})$ series.

It is also important to consider $\operatorname{REE}(\mathrm{OH})_{3}(\mathrm{ss})$ involved in the detritus particulate material. Such hydroxide-like REE may be in reaction with REE carbonate complexes in seawater. This situation can be described by the two successive reactions:

$$
\mathrm{MO}_{1.5}(\mathrm{ss})+(3 / 2) \mathrm{H}_{2} \mathrm{O}(\mathrm{l})=\mathrm{M}(\mathrm{OH})_{3}(\mathrm{ss}),
$$

$$
\begin{aligned}
\mathrm{M}(\mathrm{OH})_{3}(\mathrm{ss})+ & 2 \mathrm{CO}_{3}{ }^{2-}(\mathrm{aq})+3 \mathrm{H}^{+}(\mathrm{aq}) \\
& =\mathrm{M}\left(\mathrm{CO}_{3}\right)_{2}{ }^{-}(\mathrm{aq})+3 \mathrm{H}_{2} \mathrm{O}(\mathrm{l}) .
\end{aligned}
$$

The condition of the reaction (15), in general, is not the same as that for the reaction (14). We understand that the reaction (15) for hydration of REEO$_{1.5}$ does not produce a large tetrad effect because of the same reason mentioned just before. Only the reaction (14) is important. Hence, our previous discussion by using the reaction (4) are totally replaced by that based on the reaction (14);

$$
\begin{aligned}
& \log \left\{\mathrm{m}(\mathrm{M}, \text { tot. }) / \mathrm{m}\left(\mathrm{M}(\mathrm{OH})_{3}\right)\right\} \\
= & \left\{\Delta \mathrm{G}_{\mathrm{f}}^{\circ}\left(\mathrm{M}(\mathrm{OH})_{3}\right)-\Delta \mathrm{G}_{\mathrm{f}}^{\circ}\left(\mathrm{M}\left(\mathrm{CO}_{3}\right)_{2}{ }^{-}, \mathrm{aq}\right)\right\} / 2.303 \mathrm{RT} \\
& +\log (\phi+1)+\log \left\{\lambda\left(\mathrm{M}(\mathrm{OH})_{3}\right) / \gamma\left(\mathrm{M}\left(\mathrm{CO}_{3}\right)_{2}{ }^{-}, \mathrm{aq}\right)\right\} \\
& +\log \left\{\mathrm{f}\left(\mathrm{M}(\mathrm{OH})_{3}\right)\right\}+\text { constant. }
\end{aligned}
$$

There are no essential differences in the discussion between the two expressions of (12) and (16). The constraint (13) as to the REE mass balance in seawater-particulate systems is modified to

$$
\begin{aligned}
& \mathrm{C}_{\mathrm{p}} \cdot \mathrm{m}\left(\mathrm{M}(\mathrm{OH})_{3}\right) \\
& \quad>\mathrm{m}\left(\mathrm{MCO}_{3}^{+}, \mathrm{aq}\right)+\mathrm{m}\left(\mathrm{M}\left(\mathrm{CO}_{3}\right)_{2}^{-}, \mathrm{aq}\right) .
\end{aligned}
$$

In our discussion as above, the three particulate REE forms of (a) REEO $_{1.5}$ (ss) in detritus particulate, (b) $\operatorname{REE}(\mathrm{OH})_{3}(\mathrm{ss})$ in authigenic particulate, and (c) $\operatorname{REE}(\mathrm{OH})_{3}(\mathrm{ss})$ in detritus particulate, have been distinguished rather intentionally. In fact, the three forms could not be equally reactive with REE carbonate complexes in seawater under normal 
earth's surface conditions. The authigenic particulate $\mathrm{REE}(\mathrm{OH})_{3}(\mathrm{ss})$ must be the most reactive. How much amount of reactive $\operatorname{REE}(\mathrm{OH})_{3}(\mathrm{ss})$ is involved in average crustal materials like NASC? In this context, we will pay our attention to the slightly irregular variations of fourth tetrad curves of the seawater REE patterns in Fig. 4. The irregular fourth tetrads are suggesting the involvement of particulate $\mathrm{REE}(\mathrm{OH})_{3}(\mathrm{ss})$ as below.

Why are the fourth tetrad curves somewhat irregular?

The REE patterns of average Pacific deep water normalized by NASC and by the average deepsea nodule are quite sub-parallel with each other. Their first, second, and third tetrads exhibit commonly concave curves, but their fourth tetrads are slightly irregular. Also the fourth tetrads of the NASC-normalized REE patterns for the two shallow seawater sample show apparently linear variations rather than concave ones. We think that the irregularities in the fourth tetrad are related to the two facts: (i) the particulate REE in reaction with seawater could be $\operatorname{REE}(\mathrm{OH})_{3}(\mathrm{ss})$ rather than chemically inert REEO $_{1.5}(\mathrm{ss})$, and (ii) the REE abundances in such particulate REE are not exactly parallel with those in NASC, because the average shale is composed of various particulate REE forms.

In the four seawater REE patterns in Fig. 4, only the pattern of average Pacific deep water normalized by the average Pacific deep-sea nodule is most likely to correspond to the equilibrium relationship of Eq. (16). The coordination states of the three heaviest $\mathrm{REE}^{3+}(\mathrm{Tm}, \mathrm{Yb}$, and $\mathrm{Lu})$ in $\mathrm{REE}(\mathrm{OH})_{3}(\mathrm{ss})$ series coprecipitated with $\mathrm{Fe}(\mathrm{OH})_{3}$ are slightly different from those of the other light REE due to a structural change across the $\mathrm{REE}(\mathrm{OH})_{3}(\mathrm{ss})$ series (Kawabe and Ohta, 1996). In the pure crystalline $\mathrm{REE}(\mathrm{OH})_{3}$ series, they have hexagonal crystal structures $\left(\mathrm{P}_{3} / \mathrm{m}\right)$ except the heaviest $\mathrm{Lu}(\mathrm{OH})_{3}$. Only $\mathrm{Lu}(\mathrm{OH})_{3}$ with a cubic crystal structure (Im3) has been reported (Mullica and Milligan, 1980). The coordination polyhedrons of $\mathrm{REE}^{3+}$ ions in the pure crystalline $\operatorname{REE}(\mathrm{OH})_{3}$ series change from tricapped trigonal prisms $(\mathrm{CN}$ =9) to octahedrons $(\mathrm{CN}=6)$ at between $\mathrm{Yb}$ and Lu. The coordination states of $\mathrm{Tm}^{3+}, \mathrm{Yb}^{3+}$ and $\mathrm{Lu}^{3+}$ in $\mathrm{REE}(\mathrm{OH})_{3}(\mathrm{ss})$ of the deep-sea nodule are slightly different from those of the other $\mathrm{REE}^{3+}$. This produces the small irregularity in the fourth tetrad of the REE pattern for the average Pacific deep water normalized by the deep-sea nodule. The irregular fourth tetrad becomes a smooth concave curve, if we correct the structural change effect on the three heaviest REE. Our tentative corrections are shown in Fig. 4 by the dotted curve. They make the tetrad effect variation across the series regular.

The NASC-normalized REE pattern of the average Pacific deep water in Fig. 4 could satisfy the equilibrium relationship of (16) only in a rough approximation. NASC may be an approximate substitute for the deep-sea nodule which is actually in the reaction relation of (14). Apparently linear variations of the fourth tetrads of the NASC-normalized REE patterns for the two shallow seawater samples are also related to this situation. The REE abundances in NASC are similar to those in real particulate REE equilibrated with the respective shallow waters, but they are not the same. If the REE concentration ratios between the average Pacific deep water and the Pacific deep-sea nodule are the equilibrium concentration ratios for the reaction (14), then actual particulate $\operatorname{REE}(\mathrm{OH})_{3}(\mathrm{ss})$ in equilibrium with each shallow seawater has slightly smaller $\mathrm{Lu} / \mathrm{Er}, \mathrm{Yb} / \mathrm{Er}$, and $\mathrm{Tm} / \mathrm{Er}$ ratios than NASC.

Here we conclude that the direct cause of seawater tetrad effect is the ligand-exchange reaction of (14) between particulate $\operatorname{REE}(\mathrm{OH})_{3}(\mathrm{ss})$ and REE carbonate complexes under the condition of (17). The reaction (4) involving particulate REEO $_{1.5}$ (ss) may be less important in actual seawater environments. The seawater REE patterns characterized commonly by concave tetrad curves with slightly irregular fourth tetrads, imply the importance of $\operatorname{REE}(\mathrm{OH})_{3}(\mathrm{ss})$ in real particulateseawater systems. 
Seawater tetrad effect copied onto marine authigenic phases

Piepgras and Jacobsen (1992) argued that the REE patterns for ocean seawater samples normalized by NASC or average river water suspended loads are approximately the reciprocal of the apparent REE partition coefficient between seawater particulate matter and seawater solution. They assumed that the total REE of detritus particulate matter in ocean waters are exceedingly less than total REE dissolved in the respective seawater solutions. This situation is opposite to ours, but their interpretation about shale-normalized REE patterns of seawater is eventually similar to ours. However, they did not pay attention to the zig-zag variation in the apparent partition coefficients across the REE series. We emphasize that the apparent REE partition coefficients are to be discussed in conjunction with the ligand-exchange reaction (14) in the seawater environment with dominant particulate $\operatorname{REE}(\mathrm{OH})_{3}(\mathrm{ss})$.

Furthermore, according to Sholkovitz et al. (1994), the reactive ocean particulate matter is largely composed of authigenic phases formed as surface coatings of finer detritus particles in ocean seawater. Hence, the NASC-normalized seawater REE pattern does not correspond to the reciprocal of the apparent partition coefficient for the pair of detritus particulate matter and seawater solution. The particulate material in seawater is not detritus but virtually authigenic, although the REE patterns of NASC and the authigenic phases are actually sub-parallel with each other. The situation is rather comparable with the reaction step (3) for REE partitioning between seawater and carbonate rocks.

The REE characteristics of authigenic materials formed in contact with a vast amount of seawater, can be explained by the seawater REE having already the tetrad effect signature and by the apparent partition coefficients. But they cannot explain the seawater REE and the origin of seawater tetrad effect, as far as the total amount of REE in each authigenic phase is far less than the total REE dissolved in seawater solution.

The process to copy the seawater tetrad effect onto the marine authigenic phase is not the process to produce the original seawater tetrad effect. If the copying process is perfect, the authigenic phase possesses the seawater tetrad effect. The tetrad effects observed in marine carbonate rocks like JDo-1 are just such cases of almost perfect copying. On the other hand, the copying process onto authigenic marine $\mathrm{Mn}-\mathrm{Fe}$ oxyhydroxide is another special example, in which the original seawater tetrad effect is erased almost perfectly. The copying reaction itself is similar to just the reverse of the original formation reaction. This is the reason why no significant seawater-type tetrad effect can be seen in the chondrite-normalized REE patterns of deep-sea nodules despite their marine authigenic nature.

What is meant by the logarithmic scale in MasudaCoryell plot?

Finally, we will comment on Masuda-Coryell plot (Masuda, 1962; Coryell et al., 1963) from our results here. The use of logarithmic REE concentration ratios characterizes the Masuda-Coryell plot. We interpret that it is related to the logarithmic activity quotient in the Gibbs free energy. change for a ligand-exchange reaction of $\mathrm{REE}^{3+}$ like (4) and (14). If Masuda-Coryell plot is only a practical technique to eliminate the saw-toothed abundance variation between REE of odd and even atomic numbers as in Henderson (1984), each normalized abundance is not necessarily expressed only by its logarithm. The logarithmic scale in Masuda-Coryell plot is related to the chemical potential $\mu_{\mathrm{i}}=\mu_{\mathrm{i}}{ }^{*}+\mathrm{RT} \ln \left(\mathrm{a}_{\mathrm{i}}\right)$ for homogeneous mixtures.

The successive chains of REE partitioning reactions like (1), (2) and (3) are also important for understanding chondrite-normalized REE patterns of geochemical samples. Going from each geochemical sample to the chondritic material along the reaction chains is tracing the geochemical history of its REE back to the very beginning of the solar system. Hence, the chondrite-normalized REE pattern for any geochemical sample indicates the integral REE fractionation over its geochemical history since the early stage of our solar sys- 
tem. Even if we normalize one geochemical sample by another, both of which are not in a direct reaction relation, the resultant REE pattern indicates the difference in their integral REE fractionations. From this point of view, we can understand the tetrad effect variations in chondritenormalized REE patterns of seawater and marine carbonate rocks. The successive chains of REE partitioning and Gibb's chemical potentials ensure the importance and practical usefulness of MasudaCoryell plot in REE geochemistry.

\section{CONCLUSIONS}

(1) Our REE data by ICP-AES for JDo-1 (a GSJ carbonate reference sample), when normalized by the recent REE data for seawater by ICP-MS and ID-MS, exhibit fairly smooth patterns except for Ce. We have used the simple relationship to estimate the monoisotopic REE ( $\mathrm{Pr}, \mathrm{Tb}, \mathrm{Ho}$, and $\mathrm{Tm})$ concentrations compatible with the widely accepted ID-MS data as seawater REE (Piepgras and Jacobsen, 1992). For the same purpose, we have also used the reported seawater REE data by ICP-MS.

(2) The monoisotopic REE concentrations estimated by our ICP-AES data for JDo-1 and the ICP-MS data for seawater are in good agreement. Similarly, the monoisotopic REE abundances in the Antarctic bottom water (AABW) reported by German et al. (1995) have also been estimated. Eventually the seawater REE patterns exhibit concave tetrad effect variations when normalized by either chondrite or average shale. There is no room for doubt as to the seawater tetrad effect, but its origin is open to debate.

(3) We have proposed that the seawater tetrad effect originates from the REE partitioning process described by the ligand-exchange reactions of $\mathrm{REE}^{3+}$ between particulate $\mathrm{REE}$ and $\mathrm{REE}\left(\mathrm{CO}_{3}\right)_{2}$ (aq) series in seawater. The particulate REE must be $\operatorname{REE}(\mathrm{OH})_{3}(\mathrm{ss})$ rather than $\operatorname{REEO}_{1.5}(\mathrm{ss})$. According to the refined spin-pairing energy theory, logarithmic equilibrium constants for the reactions exhibit a tetrad effect, when Racah parameters are different between particulate $\mathrm{REE}$ and $\operatorname{REE}\left(\mathrm{CO}_{3}\right)_{2}$ (aq) series. We inferred that Racah parameters of $\mathrm{REE}(\mathrm{OH})_{3}$ and $\mathrm{REEO}_{1.5}$ are close to each other but commonly much smaller than those parameters of $\operatorname{REE}\left(\mathrm{CO}_{3}\right)_{2}{ }^{-}(\mathrm{aq})$. This is the cause of the seawater tetrad effect.

(4) The ligand-exchange reactions occur in the particulate-seawater systems with high particulate concentrations such as shallow coastal seawater and estuarine water, and then their excessive particulate is removed from the systems as they are conveyed in water circulation, leaving the seawater solution with the tetrad effect signature. These conditions are necessary to reproduce similar seawater tetrad effects.

(5) The shale-normalized REE data for seawater samples roughly corresponds to the equilibrium REE concentration ratios between seawater solution and particulate REE. Our proposal can explain the interesting observation that marine carbonate rocks show seawater-like tetrad effects in their chondrite-normalized REE patterns but deepsea nodules do not such effects. The proposal also provides a theoretical interpretation for the Masuda-Coryell plot of geochemical samples.

Acknowledgments-We are grateful to K. Yamamoto, $\mathrm{H}$. Iwamori and M. Minami who gave information on recent studies and comments. We also thank T. Akagi and an anonymous reviewer for their critical comments. This work was supported partly by the grants Nos. 03402018 and 06453007 from the Ministry of Education, Science and Culture, Japan.

\section{REFERENCES}

Akagi, T., Shabani, A. B. and Masuda, A. (1993) Lanthanide tetrad effect in kimuraiite $\left[\mathrm{CaY}_{2}\left(\mathrm{CO}_{3}\right)_{4} \cdot 6 \mathrm{H}_{2} \mathrm{O}\right]$ : Implication for a new geochemical index. Geochim. Cosmochim. Acta 57, 2899-2905.

Anders, E. and Grevesse, N. (1989) Abundances of the elements: Meteoritic and solar. Geochim. Cosmochim. Acta 53, 197-214.

Bau, M., Dulski, P. and Möller, P. (1995) Yttrium and holmium in south Pacific seawater: Vertical distribution and possible fractionation mechanisms. Chem. Erde 55, 1-15.

Bertram, C. J. and Elderfield, H. (1993) The geochemical balance of the rare earth elements and 
neodymium isotopes in the ocean. Geochim. Cosmochim. Acta 57, 1957-1986.

Cantrell, K. J. and Byrne, R. H. (1987) Rare earth element complexation by carbonate and oxalate ions. Geochim. Cosmochim. Acta 51, 597-605.

Coryell, C. G., Chase, J. W. and Winchester, J. W. (1963) A procedure for geochemical interpretation of terrestrial rare-earth abundance patterns. $J$. Geophys. Res. 68, 559-566.

German, C. R. and Elderfield, H. (1990) Rare earth elements in the NW Indian Ocean. Geochim. Cosmochim. Acta 54, 1929-1940.

German, C. R., Matsuzawa, T., Greaves, M. J., Elderfield, H. and Edmond, J. M. (1995) Dissolved rare earth elements in the southern ocean: Cerium oxidation and the influence of hydrography. Geochim. Cosmochim. Acta 59, 1551-1558.

Gromet, L. P., Dymek, R. F., Haskin, L. A. and Korotev, R. L. (1984) The "North American shale composite": Its composition, major and trace element characteristics. Geochim. Cosmochim. Acta 48, 24692482.

Henderson, P. (1984) General geochemical properties and abundances of the rare earth elements. Rare Earth Element Geochemistry (Henderson, P., ed.), 132, Elsevier, Amsterdam.

Jørgensen, C. K. (1971) Modern Aspects of Ligand Field Theory. North-Holland, Amsterdam, 538 pp.

Jørgensen, C. K. (1979) Theoretical chemistry of rare earths. Handbook on the Physics and Chemistry of Rare Earths, Vol. 3 (Gschneider, K. A., Jr. and Eyring, L., eds.), 111-169, North-Holland, Amsterdam.

Kawabe, I. (1992) Lanthanide tetrad effect in the $\mathrm{Ln}^{3+}$ ionic radii and refined spin-pairing energy theory. Geochem. J. 26, 309-335.

Kawabe, I. (1995) Tetrad effect and fine structures of REE abundance patterns of granitic and rhyolitic rocks: ICP-AES determinations of REE and $\mathrm{Y}$ in eight GSJ reference rocks. Geochem. J. 29, 213-230.

Kawabe, I. (1996) Convex tetrad effect variations in REE abundances of "North American shale composite" and "Post-Archean Australian average shale". Geochem. J. 30, 149-153.

Kawabe, I. and Ohta, A. (1996) Experimental study on distribution coefficients of REE between Fe-Mn oxyhydroxides and aqueous solutions (I): Structural changes and tetrad effects. Abstr. 1996 Ann. Meet. Geochem. Soc. Jpn., 88.

Kawabe, I., Kitahara, Y. and Naito, K. (1991) Nonchondritic yttrium/holmium ratio and lanthanide tetrad effect observed in pre-Cenozoic limestones. Geochem. J. 25, 31-44.

Kawabe, I., Inoue, T. and Ishii, S. (1992) Remarkable fractionations of yttrium from holmium in marine deposits. Abstr. Geochem. Soc. Japan, Spring Meet., B41-06.

Kawabe, I., Inoue, T. and Kitamura, S. (1994) Comparison of REE analyses of GSJ carbonate reference rocks by ICP-AES and INAA: Fission and spectral interferences in INAA determination of REE in geochemical samples with high U/REE ratios. Geochem. J. 28, 19-29.

Kawabe, I., Toriumi, T., Ohta, A. and Kanda, S. (1995) Effective application of ultrasonic nebulizer to ICPAES analyses of REE, Y and Sc in geochemical samples. J. Earth Planet. Sci. Nagoya Univ. 42, 1-15.

Lee, J. H. and Byrne, R. H. (1993) Complexation of trivalent rare earth elements $(\mathrm{Ce}, \mathrm{Eu}, \mathrm{Gd}, \mathrm{Tb}, \mathrm{Yb})$ by carbonate ions. Geochim. Cosmochim. Acta 57, 295-302.

Masuda, A. (1962) Regularities in variation of relative abundances of lanthanide elements and an attempt to analyse separation-index patterns of some minerals. J. Earth Planet. Sci. Nagoya Univ. 10, 173-187.

Masuda, A. and Ikeuchi, Y. (1979) Lanthanide tetrad effect observed in marine environment. Geochem. $J$. 13, 19-22.

McLennan, S. M. (1994) Rare earth element geochemistry and the "tetrad" effect. Geochim. Cosmochim. Acta 58, 2025-2033.

Millero, F. J. (1979) The thermodynamics of the carbonate system in seawater. Geochim. Cosmochim. Acta 43, 1651-1661.

Millero, F. J. (1992) Stability constants for the formation of rare earth inorganic complexes as a function of ionic strength. Geochim. Cosmochim. Acta 56, 3123-3132.

Minami, M. and Masuda, A. (1997) Approximate estimation of the degree of lanthanide tetrad effect from the data potentially involving all lanthanides. Geochem. J. 31, 125-133.

Möller, P., Dulski, P. and Bau, M. (1994) Rare-earth element adsorption in a seawater profile above the East Pacific Rise. Chem. Erde 54, 129-149.

Mullica, D. F. and Milligan, W. O. (1980) Structural refinement of cubic $\mathrm{Lu}(\mathrm{OH})_{3}$. J. Inorg. Nucl. Chem. 42, 223-227.

Piepgras, D. J. and Jacobsen, S. B. (1992) The behavior of rare earth elements in seawater: precise determinations of variations in the North Pacific water column. Geochim. Cosmochim. Acta 56, 1851-1862.

Reisfeld, R. and Jørgensen, C. K. (1977) Lasers and Excited States of Rare Earths. Springer, Berlin, 226 pp.

Shabani, M. B., Akagi, T., Shimizu, H. and Masuda, A. (1990) Determination of trace lanthanides and yttrium in seawater by inductively coupled plasma 
mass spectrometry after preconcentration with solvent extraction and back-extraction. Anal. Chem. 62, 2709-2714.

Shabani, M. B., Akagi, T. and Masuda, A. (1992) Preconcentration of trace rare-earth elements in seawater by complexation with bis(2-ethlhexyl) hydrogen phosphate and 2-ethylhexyl dihydrogen phosphate adsorbed on a $\mathrm{C}_{18}$ cartridge and determination by inductively coupled plasma mass spectrometry. Anal. Chem. 64, 737-743.

Sholkovitz, E. R., Landing, W. M. and Lewis, B. L. (1994) Ocean particle chemistry: The fractionation of rare earth elements between suspended particulates and seawater. Geochim. Cosmochim. Acta 58, 1567-1579.
Taylor, S. R. and McLennan, S. M. (1988) The significance of the rare earths in geochemistry and cosmochemistry. Handbook on the Physics and Chemistry of Rare Earths, Vol. 11 (Gschneider, K. A., Jr. and Eyring, L., eds.), 485-578, Elsevier, Amsterdam.

Zhang, J., Amakawa, H. and Nozaki, Y. (1994) The comparative behaviors of yttrium and lanthanides in seawater of the North-Pacific. Geophys. Res. Lett. 21, 2677-2680.

Zhong, S. and Mucci, A. (1995) Partitioning of rare earth elements (REEs) between calcite and seawater solutions at $25^{\circ} \mathrm{C}$ and $1 \mathrm{~atm}$, and high dissolved REE concentrations. Geochim. Cosmochim. Acta 59, 443453. 